Research Article

\title{
The Method of Measuring the Agglomeration Degree of High-Tech Industries and Its Influence Mechanism: Taking Guangdong Province as an Example
}

\author{
Li-na Han $\mathbb{D}^{1}$ and Yi-xiao Song $\mathbb{C}^{2}$ \\ ${ }^{1}$ Guangdong Institute of Scientific \& Technical Information, Guangzhou 510033, China \\ ${ }^{2}$ School of Business Administration, Guangdong University of Finance \& Economics, Guangzhou 510320, China \\ Correspondence should be addressed to Yi-xiao Song; songyixiao1@sina.com
}

Received 1 March 2021; Revised 13 April 2021; Accepted 27 April 2021; Published 8 May 2021

Academic Editor: Carlos Llopis-Albert

Copyright (C) $2021 \mathrm{Li}$-na Han and Yi-xiao Song. This is an open access article distributed under the Creative Commons Attribution License, which permits unrestricted use, distribution, and reproduction in any medium, provided the original work is properly cited.

\begin{abstract}
This paper selects the Herfindahl-Hirschman index and the Moran index to study the overall agglomeration and spatial distribution of high-tech industries in Guangdong, a province of China. The location entropy, dynamic agglomeration index, and output value share are also used in this study to measure the agglomeration and changes that occur in high-tech industries in various cities of Guangdong Province. The relevant data of high-tech industries for the province is collected between 2013 and 2018. Our results show that Guangdong Province's overall agglomeration of high-tech industries strengthened between 2013 and 2018, but industrial transfer occurred within the cities in the Pearl River Delta region to a certain extent. Regional international trade, R\&D investment and patent output of the whole society, number of local scientific research personnel, economies of scale, communication level, and local taxation policies are the main factors contributing to the changes in the agglomeration of hightech industries. Guangdong should create an open environment to increase R\&D investment and expand the scale of R\&D personnel and economy as well as strengthening intellectual property protection and communication level. Preferential taxation policies should be also implemented to accelerate the agglomeration of high-tech industries.
\end{abstract}

\section{Introduction}

In recent development, the total economic output of Guangdong Province has reached 10 trillion yuan. Guangdong Province is now in a vital adjustment period to transform its economic development model and growth momentum. Enhancing innovation-driven development momentum and accelerating the construction of a power system for high-quality development constitute the key path Guangdong must take to overcome the obstacles in the following stage. The development trend of high-tech industry agglomeration has played a key role in improving the quality of economic development and warrants attention [1].

Academic research on the agglomeration of high-tech industries can be mostly summarized into the following five categories. The first one is the research on the state of industrial agglomeration. For instance, Paul [2] used the spatial Gini coefficient to analyze the industrial agglomeration of the manufacturing industry in the US. The results showed that most manufacturing industries in the US experienced agglomeration. Ellison and Glaeser [3] utilized the EG index to analyze the four-digit industries in the US, and their results also showed that most four-digit industries in the US were increasingly agglomerated. Maurel and Sédillot [4] selected MS index to analyze two-digit and four-digit industries, respectively, in France to reach the same conclusion for France. Braunerhjelm and Dan [5] analyzed the data of the Swedish manufacturing industry in the past 20 years from 1975 to 1993 to find that the degree of agglomeration of the Swedish manufacturing industry has increased year by year. Furthermore, Brülhart and Traeger [6] studied the agglomeration of manufacturing in Western 
European countries from 1975 to 2000. Leahy et al. [7] studied the agglomeration of manufacturing in Australia from 1994 to 1997 . Their results showed that the degree of agglomeration of the manufacturing industries in these countries increased year by year. Paluzie [8] in their study examined industrial agglomeration in Spain from 1979 to 1992 and found that the degree of industrial agglomeration in Spain did not change much during the researched period. Dumais et al. [9] studied the agglomeration of American manufacturing from 1972 to 1992 and concluded that the degree of agglomeration in the US declined slightly during this period. He et al. [10] found that the agglomeration of economy was proven to significantly promote geographic agglomeration of manufacturing, but it was more important at a county level, and industrial linkages failed to promote geographic agglomeration of Chinese industries. Lei [11] used interprovincial panel data to study China's electronic information manufacturing industry and reached the conclusion that the lack of regional roots in the industrial value chain was the reason why China's electronic information manufacturing industry cannot form an advantageous industrial agglomeration. All the research above shows that the industrial agglomeration situations are different and changing across various countries. The second category is the research on the influencing factors of industrial agglomeration. A wide range of research on industrial agglomeration is still carried out based on the three factors proposed by Marshall. For instance, Dumais et al. [9] studied the agglomeration of manufacturing industries in the US and found that labor sharing is the most influential factor. Baldwin et al. [12] examined the agglomeration of manufacturing industries in Canada and found that the three elements proposed by Marshall appeared to have a promoting effect. Scholars also try to identify additional impact factors on industrial agglomeration. For instance, Ellison and Glaeser [3], Hanson [13], Paluzie et al. [14], Combes and Lafourcade [15], Hanson [16], and Bosker et al. [17] argued that resource endowment, regional economic integration, economies of scale, transportation costs, market potential, and labor mobility can have some effects on industrial agglomeration. The third category is the study of agglomeration of high-tech industries. Hill and Naroff [18] argued that geographic spatial location can promote the agglomeration of high-tech industries. However, Wood and Parr [19] presented the argument that the agglomeration of high-tech industries could help reduce transportation and transaction costs, therefore promoting enterprise exports and enhancing the overall competitiveness of enterprises. Liu and $\mathrm{Wu}$ [20] found that four factors, namely, climate environment, infrastructure, regional knowledge spillover capacity, and regional technical strength, had a significant impact on the location selection of high-tech enterprises in China. Yao and $\mathrm{Xu}$ [21] examined the formation mechanism of high-tech industry agglomeration and argued that the improvement of the agglomeration level is the main change direction and development trend of China's high-tech industry. In another study, Gao [22] proposed that the agglomeration effects of high-tech industries included resource sharing effects and information spillover effects. Liu et al.
[23] argued that China's high-tech industrial clusters present in the biological industries were at the middle and low end of the global value chain. Hart [24] believed that the agglomeration of high-tech industries could attract high-end talents and thus improve corporate team efficiency to generate higher performance. Cieślik and Ghodsi [25] revisited the existing empirical evidence on the effects of various agglomeration externalities and market structure on employment growth in the high-tech industries of the European Economic Area (EEA) and found that localization and urbanization externalities did not appear to have an impact on growth. Zandiatashbar et al. [26] found that hightech industries prefer dense, walkable, transit-accessible places. The fourth research direction is related to the transfer of high-tech industries. Mao [27] proposed that industrial clustering transfer was a new trend of industrial transfer. The researcher in their study clarified the connotation, motivation, mode, and effect of industrial clustering transfer. Su and Sun [28] found that the differences in factor cost and transaction cost among three Chinese regions, Jiangsu, Zhejiang, and Shanghai, were made part of manufacturing industry and tertiary industry transfer and assembly among Jiangsu, Zhejiang, and Shanghai themselves. Luo et al. [29] stated that technology-intensive industries transfer occurred from the Central and Western regions to the East. Mao et al. [30] found that the cluster transfer of high-tech industries in Jiangsu Province of China generally presented a spatial pattern of "two belts and one line." Cheng [31] believed that regional industrial transfer demonstrated new characteristics such as industrial transfer stickiness and industrial cluster transfer in recent years. Tao et al. [32] research supported the argument that industrial gradient transfer could significantly promote its level of agglomeration. Tu et al. [33] identified and subsequently established the conditions for determining industrial agglomeration and diffusion to conduct an empirical study on the time and space transfer of high-tech industries in Fujian Province. The results from the said empirical study show that the coastal areas of industrial diffusion were in fact distributed in a stepped manner. The fifth research direction is on effects of industrial agglomeration. Yang et al. [34] proposed in their study that industrial agglomeration can promote the increase of total factor productivity through knowledge or technology spillover and diffusion of technological innovation achievements. Wang and Wang [35] argued that diversification agglomeration of high-tech industry could improve China's labor productivity; however, this positive effect was significant but not robust. Specialization agglomeration would restrain the improvement of labor productivity. Zhang et al. [36] proposed that specialization and diversification, respectively, restrain and promote regional innovation activities in high-tech industries. Li et al. [37] found that the increase of agglomeration can promote economic growth in the early stage of agglomeration, but agglomeration would become a resistance factor of economic growth after development reaches certain stage. Guo et al. [38] proposed that both the flow of human capital and the agglomeration of hightech industry demonstrated significant positive effects on promoting regional economic growth, and they interacted 
with each other during the mechanism. Moreover, the result of Sun et al. [39] indicates that industrial agglomeration has a significant and positive effect on patent output of high-tech industries. However, Dong et al. [40] argue that despite the positive effects, industrial agglomeration can also lead to pollution agglomeration.

At present, although scholars have conducted a lot of research on industrial clusters, there is little research on the characteristics and the formation mechanism of high-tech industry agglomeration. In particular, the dynamic research on the agglomeration of high-tech industries combined with the new economic geography is rarely done by scholars. In addition, scholars lack in-depth exploration of the formation mechanism of the agglomeration of high-tech industries. They are still stuck in the analysis framework of general industrial agglomeration and rarely carry out in-depth research in combination with the characteristics of high-tech industries. Based on the above-mentioned scholars' research, taking Guangdong Province as an example, this paper comprehensively uses various indexes to analyze the trend and characteristics of high-tech industry agglomeration. This paper also groundbreakingly combines the classic theory of industrial agglomeration and new economic geography to establish an analysis framework for the influence mechanism of high-tech industry agglomeration, and uses factor analysis, principal component analysis, and other methods to conduct empirical research on the factors affecting high-tech industry agglomeration. The results of this paper can enrich and expand the theories and methods of high-tech industry agglomeration and lays a certain foundation for later research into high-tech industry agglomeration, which has important theoretical significance.

It is generally agreed on that high-tech industrial clusters tend to play a key supporting role in promoting economic quality, efficiency, and power. Cultivating and developing high-tech industrial clusters can lay a solid foundation for high-quality economic development. Therefore, the authority of Guangdong Province issued a document on May 20, 2020, titled "Opinions of the People's Government of Guangdong Province on the Cultivating and Developing Strategic Pillar Industrial Clusters and Strategic Emerging Industrial Clusters." The purpose of this document is to illustrate the plan of developing several industrial clusters with global competitiveness by cultivating and developing ten strategic pillar industrial clusters and ten strategic emerging industrial clusters; most of these 20 industrial clusters are high-tech industrial clusters. Therefore, the researchers argue that studying the agglomeration characteristics, spatial pattern, and evolution mechanism of hightech industries also has important practical value.

\section{Measurement and Judgment of the Agglomeration Situation of High- Tech Industries}

Industrial agglomeration is a process during which certain industries are concentrated in the same geographic area, where relevant technology, capital, labor, and other elements are continuously attracted from other places [35]. Based on previous studies, this paper aims to compare and analyze the methods of measuring industrial agglomeration and subsequently summarize and screen the following measuring methods by combining actual conditions in Guangdong Province and data availability conditions.

2.1. Herfindahl-Hirschman Index (HHI). The Herfindahl-Hirschman index, also known as the Herfindahl index, is an index that measures industry concentration from the perspective of market share. It is considered as a comparatively better index among related measurement indexes of industrial concentration. The formula is as follows:

$$
\text { HHI }=\sum_{i=1}^{n}\left(x_{i} / X\right)^{2} .
$$

In the above function, $X$ represents the total market size; in this study, the province's high-tech product output value is used to measure the total market size. $x_{i}$ represents the market size of enterprise $i$, which is measured by the output value of high-tech products in area $i . \mathrm{N}$ represents the number of enterprises present in the industry, here referring to the number of selected regions. If all high-tech industries are concentrated in one area, $\mathrm{HHI}$ would have the maximum value, 1 . If the scale of high-tech industries in all areas is identical, then $\mathrm{HHI}=1 / n$. Therefore, the larger the value of $\mathrm{HHI}$ is, the higher the concentration of the industry is.

2.2. Spatial Autocorrelation Index. The purpose of spatial autocorrelation analysis is to determine whether variables are spatially correlated and the degree of correlation between them. Moran's I (Moran index) proposed by Anselin is selected as the global spatial autocorrelation test index. The formula for the index is presented as follows:

$$
\begin{aligned}
I & =\frac{\sum \sum W_{i j}\left(x_{i}-\bar{x}\right)\left(x_{j}-\bar{x}\right)}{S^{2} \sum \sum W_{i j}}, \\
W_{i j} & = \begin{cases}1, & \text { when area } i \text { and area } j \text { are adjacent, } \\
0, & \text { when area } i \text { and area } j \text { are not adjacent. }\end{cases}
\end{aligned}
$$

In the above formula, $S^{2}=(1 / n) \sum_{i=1}^{n}(x-\bar{x})^{2}$; $\bar{x}=(1 / n) \sum_{i=1}^{n} x_{i}$; and $x_{i}$ and $x_{j}$ represent the output value of high-tech products in areas $i$ and $j$, respectively. $n$ is the number of cities in the research area, and $W_{i j}$ is the spatial weight matrix.

$I$ is the global space self-phase index. Its value range is set as $[-1,1]$. When $I>0$, it would indicate that there is a positive correlation between the output values of high-tech products in different areas. The closer to 1 the $I$ is, the higher the degree of agglomeration would be. When $I<0$, this would indicate that there is a negative correlation between the output values of high-tech products in different areas. When $I=0$, there would be no spatial autocorrelation between the output values of high-tech products in different areas. 
The $Z$ test is generally used to test the significance of the $I$ value. The formula is as follows:

$$
Z=\frac{I-E[I]}{\sqrt{V[I]}} .
$$

In the above formula, $E[I]$ denotes the mean value of $I$, and $V[I]$ represents the variance of $I$. When $Z>1.96$, Moran's $I$ is significant, and not significant otherwise.

2.3. Location Entropy (Static Agglomeration Index). The location entropy was first determined by P. Haggett and used to capture the degree of concentration present in a certain industry's specialization. It is also called the specialization rate. The formula for location entropy is as follows:

$$
L Q_{x y}=\frac{q_{x y} / q_{x}}{Q_{y} / Q} .
$$

Further deriving the formula, we can obtain the following:

$$
L Q_{x y}=\frac{q_{x y} / Q_{y}}{q_{x} / Q} .
$$

In the above formula, $q_{x y}$ represents the output value of industry $x$ in area $y ; q_{x}$ represents the total output value of industry $x$ in the province; $Q_{y}$ denotes the value of the output of all industries in area $y$; and $Q$ represents the total output value of all industries in the province. Generally speaking, $L Q_{x y}>1$ would suggest that the industry $x$ in area $y$ has advantages in the whole province; $L Q_{x y}<1$ would suggest that industry $x$ in area $y$ has disadvantages in the whole province. According to the availability of data, $q_{x y} / Q_{y}$ is measured by the proportion of the output value of hightech products to the total industrial output value of industries above designated size (industrial corporations with main business income of 20 million yuan and above) in area $y ; q_{x} / Q$ is a ratio measured by the proportion of the output value of high-tech products to the total industrial output value of industries above designated size in the whole province.

2.4. Dynamic Agglomeration Index. The dynamic agglomeration index refers to an index that reflects the dynamic changes of a certain industry agglomeration situation. The calculation formula is as follows:

$$
D_{x y(0-t)}=\frac{b_{x y(0-t)}}{\sum_{y=1}^{n} b_{x y(0-t)}} .
$$

In the above formula, $D_{x y(0-t)}$ represents the dynamic situation of the agglomeration degree of the output value of a specific industry $x$ in a specific area $y$ from time 0 to $t ; b_{x y(0-t)}$ is the growth rate of the output value of a specific industry $x$ in a specific area $y$ from 0 to $t ; \sum_{y=1}^{n} b_{x y(0-t)}$ denotes the average growth rate of the output value for local industries from 0 to $t$. $D_{x y(0-t)}>1$ would mean that industry agglomeration has enhanced; $0<D_{x y(0-t)}<1$ would mean that the industrial agglomeration is weakened [28].

\section{Analysis of the Agglomeration of High-Tech Industries in Guangdong Province}

3.1. Data Source. Data used in this paper are mostly derived from the 2013-2018 "Guangdong Province Science and Technology Statistical Yearbook," as well as the statistical yearbooks and statistical bulletins of each city in Guangdong Province. Limited by the availability of data, this paper chooses 2013 as the starting time point for the study. Due to the lag in data update, 2018 is the end year.

3.2. The Concentration of the Whole Province's High-Tech Industries. We argue that understanding the development pattern of high-tech industrial clusters is the basis for analyzing its development trend. By computing the Herfindahl-Hirschman index of the high-tech industry in Guangdong Province according to (1), we are able to obtain the result shown in Figure 1. From the perspective of HHI, the degree of agglomeration of Guangdong Province's hightech industries was seen to be weakened from 2014 to 2016 and later enhanced from 2016 to 2018. According to the trend line of the Herfindahl-Hirschman index of high-tech industries from 2013 to 2018, the agglomeration of high-tech industries in Guangdong Province has gradually enhanced from 2013 to 2018 in general. This is mainly because Guangdong Province experienced a transfer of traditional industries after 2012, which caused the original industrial clusters to evolve from concentration to move towards decentralization, which resulted in a decline in the degree of industrial agglomeration from 2014 to 2016. With the rise of high-tech enterprises, the original industrial parks were upgraded to high-tech parks, high-tech projects and infrastructure construction in the area continuously improved, and emerging industrial clusters gradually formed as a result. Moreover, the agglomeration capacity appeared to be stronger than before, and the industrial quality was also higher, which was reflected in the improvement of degree of industrial agglomeration after 2016.

In the development process of various cities, there may be a certain spatial correlation between high-tech industries in different cities due to the mutual influence and the spatial spillover effect of knowledge. According to (2) and (3), Moran's $I$ index of the output value of high-tech products in Guangdong Province is calculated (Table 1). It can be seen that Moran's $I$ index is between 0 and 1 . All the $P$ values are less than 0.05 , and all the $Z$ values are greater than 1.96 . This would indicate that Moran's $I$ index was in fact significant. From the perspective of time trends, Moran's I index of Guangdong Province's high-tech product output value increased year by year from 2013 to 2018, suggesting that the geographic and spatial relevance of Guangdong's high-tech industries enhanced year by year in the past 6 years. We argue that one reason that may have caused this is that Guangdong Province has continuously carried out deepened market mechanism reforms in recent years, the vertical division of industry has been continuously refined, and the logistics and transportation system has been improved to reduce production cost and closer cooperation between local 


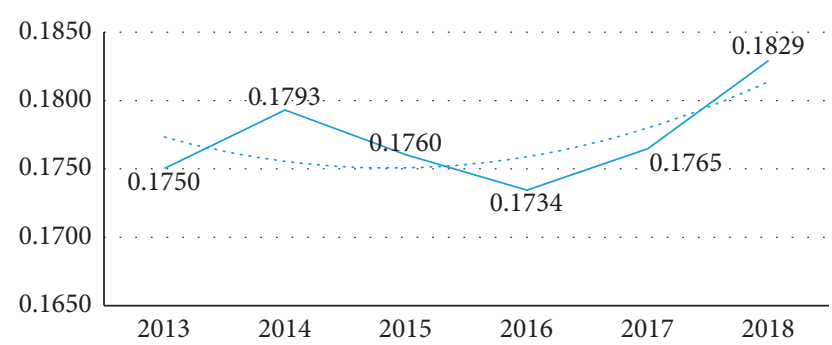

FIgure 1: The Herfindahl-Hirschman index of high-tech industries in Guangdong Province from 2013 to 2018.

TABle 1: Moran's I index of high-tech industries of Guangdong Province from 2013 to 2018.

\begin{tabular}{lcccccc}
\hline Year & 2013 & 2014 & 2015 & 2016 & 2017 & 2018 \\
\hline Moran's $I$ & 0.2617 & 0.2593 & 0.2841 & 0.3006 & 0.3216 & 0.3714 \\
$P$ & 0.026 & 0.032 & 0.019 & 0.023 & 0.014 & 0.009 \\
$Z$ & 2.3143 & 2.3760 & 2.5207 & 2.6010 & 2.8828 & 3.2981 \\
\hline
\end{tabular}

regions. Another reason is that Guangdong Province has accelerated the formation of innovative industrial clusters through various policies, the industrial chain has accelerated the gathering of upstream and downstream enterprises, and technological innovation has been gradually spread to various cities along the industrial chain. The integration of industrial technological innovation of Guangdong Province, especially with the Pearl River Delta cities at the core, has strengthened.

According to the data of the numbers of high-tech enterprises in various Guangdong cities, this paper uses the spatial analysis software GeoDa 1.14 to make a quartile map of the number of high-tech enterprises in each city of Guangdong Province in 2013 and 2018 (Figures 2(a) and 2(b) in Figure 2). Each city is divided into four levels based on the number of high-tech enterprises. The darker the graph color is, the higher the grade is, representing a greater number of enterprises. It can be seen that high-tech enterprises in Guangdong Province were mainly concentrated in the Pearl River Delta region and Qingyuan City in 2013. Among the northern, eastern, and western regions of Guangdong Province, only Shantou was in the third level. Until 2018, the distribution of high-tech enterprises in Guangdong Province did not experience drastic changes but showed a trend of increasing agglomeration. The number of high-tech enterprises in Zhuhai dropped from the fourth level to the third level, while Zhongshan rose from the third level to the fourth level. The "strong core" status of Guangzhou, Shenzhen, Foshan, and Dongguan is further highlighted. High-tech enterprises in the Chaoshan area (including Jieyang, Chaozhou, Shantou, and Shanwei) are showing additional gathering in Shantou.

Considering that high-tech enterprises may not represent the development of high-tech industries to the fullest, this paper also uses the software GeoDa 1.14 to make a quartile chart of the output value of high-tech products in each city of Guangdong Province in 2013 and 2018 (Figures 2(c) and 2(d)). According to the output value of high-tech products, each city is divided into four levels.
Similar to previous arrangement, the shade of the color represents levels of output value. It can be seen that the output value level of high-tech products in some cities (Figures 2(c) and 2(d)) and the number of enterprises (Figures 2(a) and 2(b)) have changed significantly. In some cities (such as Zhanjiang and Huizhou), product output value level is higher than the enterprise quantity level. This shows that although the number of high-tech enterprises in some cities is relatively small, they are larger in scale and higher in output value. On the contrary, in some cities, the number of enterprises is in fact higher than the level of product output value. This would suggest that although there are a large number of high-tech enterprises in some cities, the scale is not large, and the output value is not high. For example, the number of enterprises in Qingyuan City is in the third level in 2013 while the value of product output was only in the second level. Overall, the agglomeration of the distribution of high-tech products' output value appears to be higher than the agglomeration of the distribution of the number of enterprises in Guangdong Province in 2013 and 2018. The overall trend suggests that cities with large output value of high-tech products are mainly agglomerated in the Pearl River Delta.

Based on the above analysis, we can argue that the hightech industries in Guangdong Province have shown a trend of further agglomeration in geographic space over time, which does appear to be consistent with the conclusions obtained from the Herfindahl-Hirschman index and Moran's $I$ index above.

\subsection{Agglomeration of High-Tech Industries in Each City.} The location entropy of high-tech industries in 21 cities of Guangdong Province is calculated according to (5) and (6) (Figure 3). It can be seen that the location entropy of Guangzhou, Shenzhen, Zhuhai, Foshan, Huizhou, Dongguan, Zhongshan, and Yunfu exceeded 1 from 2013 to 2018. Except Yunfu, all these cities are located in the Pearl River Delta. Overall, the degree of specialized agglomeration of high-tech industries in the Pearl River Delta cities was significantly higher than that in the eastern, western, and northern cities in Guangdong Province. The location entropy of Yunfu City from 2017 to 2018 was comparatively high, as it surpassed many Pearl River Delta cities in 2018. On the one hand, the high-tech industry in Yunfu developed rapidly. In 2018, the output value of high-tech products in Yunfu City was 34.998 billion yuan, ranking 5 in Guangdong. On the other hand, Yunfu City's industries developed relatively slowly in the past two years. According to the 2018 Yunfu National Economic and Social Development Statistical Bulletin, the annual added value of industrial enterprises above designated size in Yunfu in 2018 fell by $0.1 \%$ compared with the previous year. Therefore, the output value of high-tech products in Yunfu accounted for $68.7 \%$ of the total industrial output value in 2018 which is 17.1 percentage points higher than that of the whole province. Shenzhen's location entropy expectably ranked first in the province, which demonstrated the outstanding advantages in specialization and agglomeration of high-tech industries 

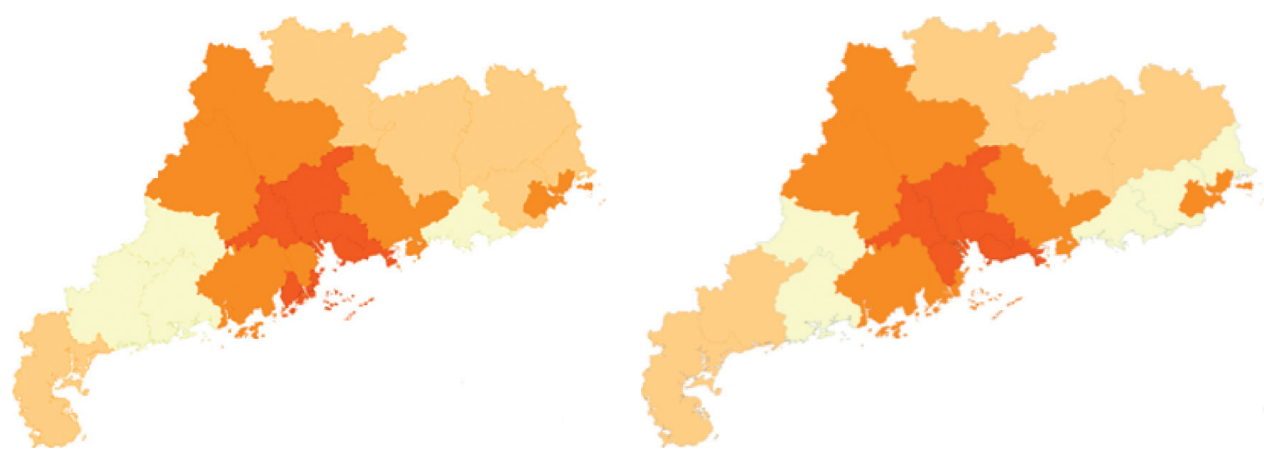

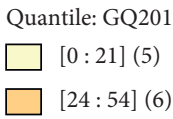

$[62: 258](6)$

[332:3222] (5)

(a)

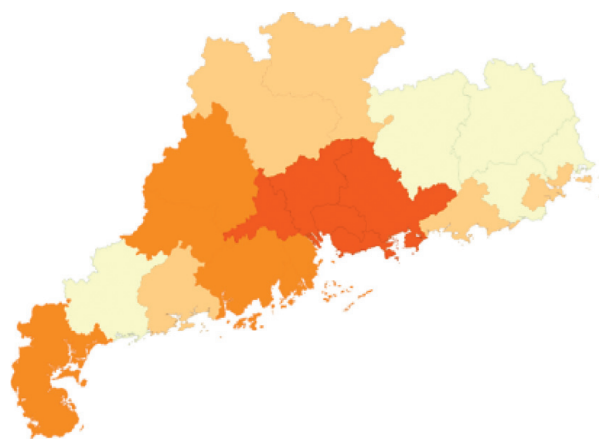

Quantile: CZ2013

$\square[0: 118.880](5)$
$\square[144.420: 222.460](6)$

(c)

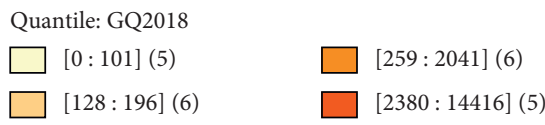

(b)

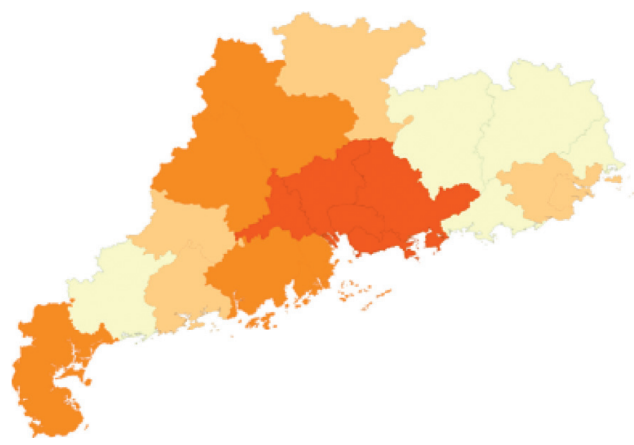

Quantile: CZ2018

$\square[0: 169.210](5)$

[242.630:429.530] (6)

(d)

Figure 2: Quartile chart of the number of high-tech enterprises and the output value of high-tech products in Guangdong Province.

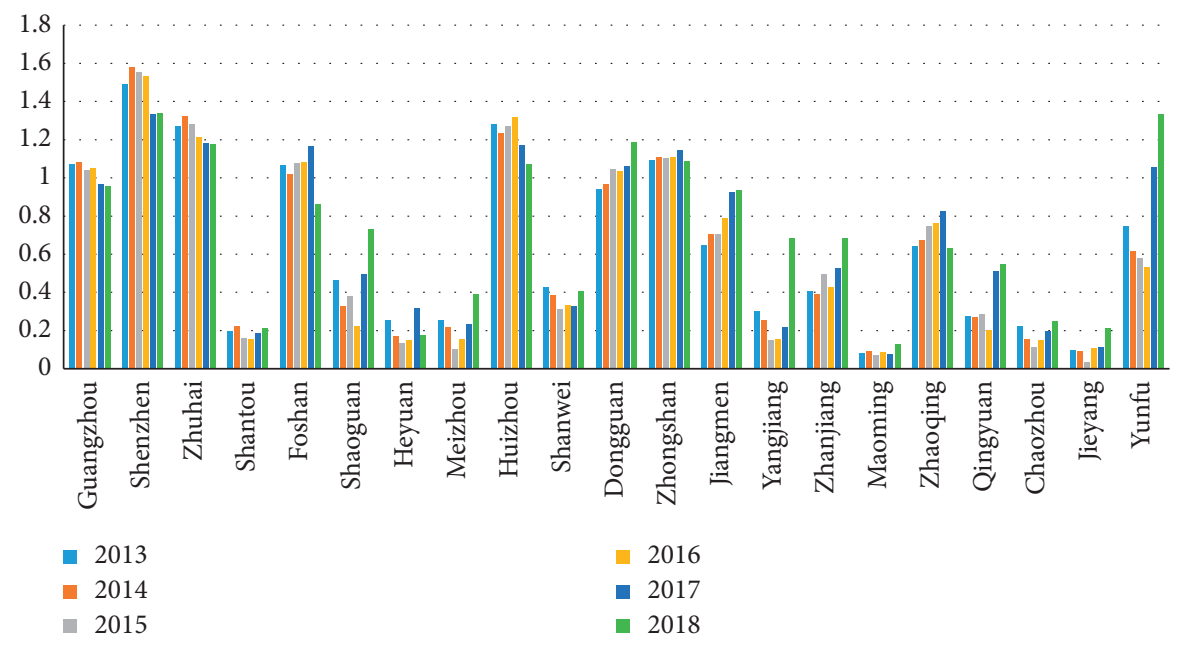

Figure 3: Location entropy of high-tech industry in different cities of Guangdong Province.

for the city. Guangzhou has no more obvious advantages in specialization and agglomeration of high-tech industries than other cities in the Pearl River Delta, and it even showed a downward trend. Especially in 2017-2018, Guangzhou's location entropy dropped to a level below 1.
To judge the state of industrial agglomeration, Mao [30] argued in their study that if the location entropy of the industry is greater than 1.12 , and the annual output value share exceeds a certain percentage, it should be considered that this industry has formed a cluster in the region. After 
examining the actual situation of Guangdong Province and the characteristics of the research data in this paper, we believe that the location entropy of the high-tech industry $L Q>1.12$, the annual output value share is more than $10 \%$, and the clusters formed in this region have relatively greater advantages in the province. The paper uses the proportion of the output value of high-tech products of each city in the whole province to represent the share of the output value of each city (Figure 4). The market share of Shenzhen's hightech product output value can be seen to be more than $30 \%$, which occupies an absolute dominant position in the province. Similarly, the market shares of Guangzhou (2013-2018), Foshan (2013-2017), and Dongguan (2016-2018) also exceeded 10\%. From this, combined with the data in Figure 3, it can be observed that the location entropy of Guangzhou and Dongguan exceeded 1.12 in 2013-2016 and 2016-2018, respectively. Therefore, we can conclude that Shenzhen, Guangzhou, Dongguan, and Foshan have formed advantageous high-tech industrial clusters. However, except for Shenzhen, the advantages of high-tech industrial clusters in these cities appear to be unstable and are constantly changing.

The dynamic agglomeration index can reflect the changes in industrial agglomeration over a certain period of time. According to (7), this paper computes the dynamic agglomeration index $D_{x y(0-t)}$ of Guangdong Province's high-tech industries (Table 2). 12 cities in Guangdong Province are seen to possess a dynamic agglomeration index of high-tech industries that are greater than 1, and 9 cities have a dynamic agglomeration index of high-tech industries that are smaller than 1 . This shows that the agglomeration of high-tech industries in 12 cities, including Shenzhen, Zhuhai, Shantou, and Shaoguan, is increasing, while the agglomeration of high-tech industries in 9 cities, including Guangzhou, Foshan, Huizhou, and Heyuan, appears to be decreasing. Overall, the agglomeration of high-tech industries in Guangdong Province increased during 2013-2018, an observation that is consistent with the conclusions obtained by the HHI index. It can be seen that although some cities have larger static agglomeration index and output value share, a downward trend in agglomeration can be observed during 2013-2018. For example, cities such as Guangzhou, Zhuhai, and Foshan have relatively large static location entropy and a large share of output value, which would suggest that the output value of high-tech products in these cities accounts for a relatively higher proportion of the total industrial output value above designated size. However, compared with other cities in Guangdong Province, especially Shenzhen and Dongguan, the growth rate is slower and below provincial average. Therefore, the dynamic agglomeration index of these cities is less than 1, and the agglomeration is weakened.

$\mathrm{He}$ [10] has pointed out the method of evaluating China's industrial geography since 1978 in their study; if the market share changes by more than $0.5 \%$, it would be considered that the industry has shifted. The high-tech industries in Guangdong Province have undergone a certain degree of dynamic transfer since 2013. According to Figure 5, we can see that, in the Pearl River Delta region,
Guangzhou, Foshan, Huizhou, Zhongshan, and Zhaoqing were the main cities which saw industry transfer outwards, while Dongguan, Shenzhen, and Jiangmen were the main cities where industries have transferred inwards. From Figure 4, although Guangdong Province's high-tech industries were mostly concentrated in the Pearl River Delta region, a certain degree of transfer still occurred within the cities in the Pearl River Delta region. The transfer from the eastern cities to the western and northern ones in Guangdong Province was not significant however. This is because Guangdong Province's high-tech industries are mainly concentrated in the Pearl River Delta region. With the increasingly fierce competition for the homogeneity of industries in the Pearl River Delta occurring in recent years, some high-tech industries have undergone small transfers within regional cities, which has a certain degree of impact on the industrial agglomeration of various cities.

\section{Analysis of the Impact Mechanism of Changes in the Agglomeration Situation of High-Tech Industries}

4.1. Theoretical and Mechanism Analysis. As one of the phenomena of industrial agglomeration, the formation mechanism of high-tech industrial agglomeration shares many similar characteristics with general industrial agglomeration, such as being affected by transportation costs, economies of scale, local demand, and costs of trade. One of the most well-known scholars who studied industrial agglomeration is Marshall, who began to study the phenomenon of industrial agglomeration in 1890 . He proposed that knowledge spillovers, international trade, and labor pools were the main factors that contributed towards industrial agglomeration. His theory was summarized as Marshallian externalities by scholars later and was widely used. For example, Ellison et al. [41] confirmed that Marshallian externalities had a significant impact on collaborative agglomeration through research on American manufacturing industries. The empirical results of Han et al. [42] demonstrated that Marshallian externalities have a significant impact on China's industrial agglomeration. With the continuous deepening of research, new economic geography and government actions have also been gradually applied to the research. Chen et al. [43] analyzed the impact of Marshallian externalities, new economic geography, government action, and other factors on the agglomeration of manufacturing in China through empirical research.

As the high-tech industry has the characteristics of high $\mathrm{R} \& \mathrm{D}$ investment and a large proportion of research and development personnel, the industrial agglomeration and the formation of clusters share some of the common characteristics of general industrial clusters while retaining their unique characteristics. For example, high-tech industries are generally less dependent on natural resource endowments and are less affected by elements such as regional minerals, agriculture, and energy. Based on this, the paper establishes an analysis framework for the factors affecting high-tech industry agglomeration that is composed 


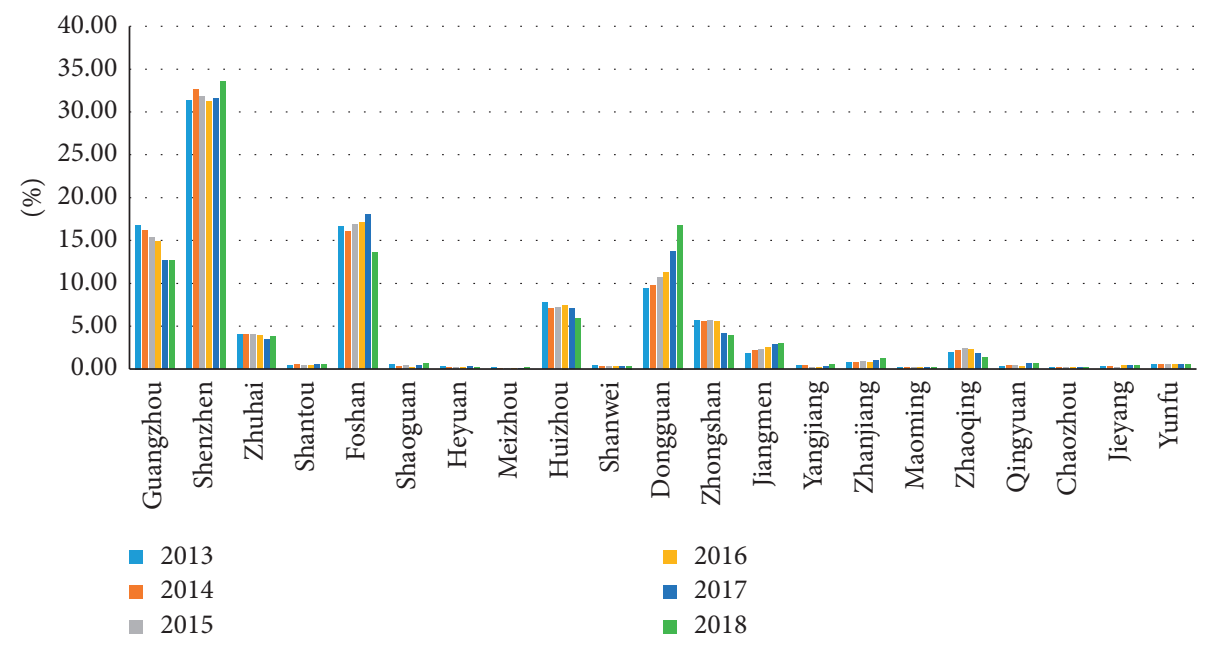

FIGURE 4: Share of output value of high-tech products in cities of Guangdong Province.

TABLE 2: Changes in the clustering status of high-tech industries in Guangdong Province from 2013 to 2018.

\begin{tabular}{lcc}
\hline City & $\begin{array}{c}\text { Dynamic agglomeration } \\
\text { index }\end{array}$ & $\begin{array}{c}\text { Agglomeration of } \\
\text { industries }\end{array}$ \\
\hline Guangzhou & 0.3183 & Weakening \\
Shenzhen & 1.1900 & Enhancing \\
Zhuhai & 0.8621 & Weakening \\
Shantou & 1.5184 & Enhancing \\
Foshan & 0.4888 & Weakening \\
Shaoguan & 1.6149 & Enhancing \\
Heyuan & 0.0409 & Weakening \\
Meizhou & 1.8966 & Enhancing \\
Huizhou & 0.3466 & Weakening \\
Shangwei & 0.7468 & Weakening \\
Dongguan & 3.1277 & Enhancing \\
Zhongshan & 0.1742 & Weakening \\
Jiangmen & 2.7112 & Enhancing \\
Yangjiang & 1.2021 & Enhancing \\
Zhanjiang & 2.5188 & Enhancing \\
Maoming & 1.7537 & Enhancing \\
Zhaoqing & 0.0867 & Weakening \\
Qingyuan & 3.5519 & Enhancing \\
Chaozhou & 1.1879 & Enhancing \\
Jieyang & 2.0530 & Enhancing \\
Yunfu & 0.7763 & Weakening \\
\hline
\end{tabular}

of three dimensions: Marshallian externalities, new economic geography, and government actions (Figure 6).

4.1.1. Marshallian Externalities. According to existing literature, the influencing factors mentioned in Marshallian externalities mostly include international trade, knowledge spillovers, and labor pools interactions. International trade is measured by the total amount of exports and the amount of foreign direct investment actually used. It mainly measures the degree of openness of the region and the cost of international trade and plays a role in the formation of hightech industries. It is generally believed that the more developed a region's foreign international trade, the faster the development of high-tech industries in this region, and the easier the formation of agglomerations. Knowledge spillover plays a crucial role in the formation of high-tech industry agglomeration. It is measured by $\mathrm{R} \& \mathrm{D}$ investment and patent output of the whole society. Knowledge spillover is divided into intraindustry and interindustry spillover. It strengthens the links between industries and promotes the agglomeration of industries through the transmission of products and technologies, as well as cooperation between enterprises. The labor pool mainly refers to the scale of employees and the number of high-quality scientific research personnel. The greater the values of these two indicators are, the easier it is to promote the agglomeration of high-tech industries.

4.1.2. New Economic Geography. It can be argued that transportation costs and economies of scale are the key factors affecting industrial agglomeration in the theory of new economic geography. This paper uses regional highway mileage and gross national product to measure these factors. In addition, the level of communication has also become an important factor that affects the location of enterprises. The higher the communication level available is, the more convenient the communication, technology dissemination, and product mailing with the outside world and the greater the possibility of high-tech industries forming agglomeration will be. This article uses business volume to measure the level of communication.

4.1.3. Government Actions. Throughout the regions where high-tech industries agglomerate, government actions are playing an increasingly important role. The government's taxation policy, scientific and technological emphasis, and investment in industry are all important factors. Generally, the more favorable the government's tax policies for hightech industries and the greater the investment in technology and industry are, the easier it will be to promote high-tech industries to grow to form specialized production areas and ultimately larger high-tech industrial clusters. The paper uses the local general public budget revenue, the proportion 


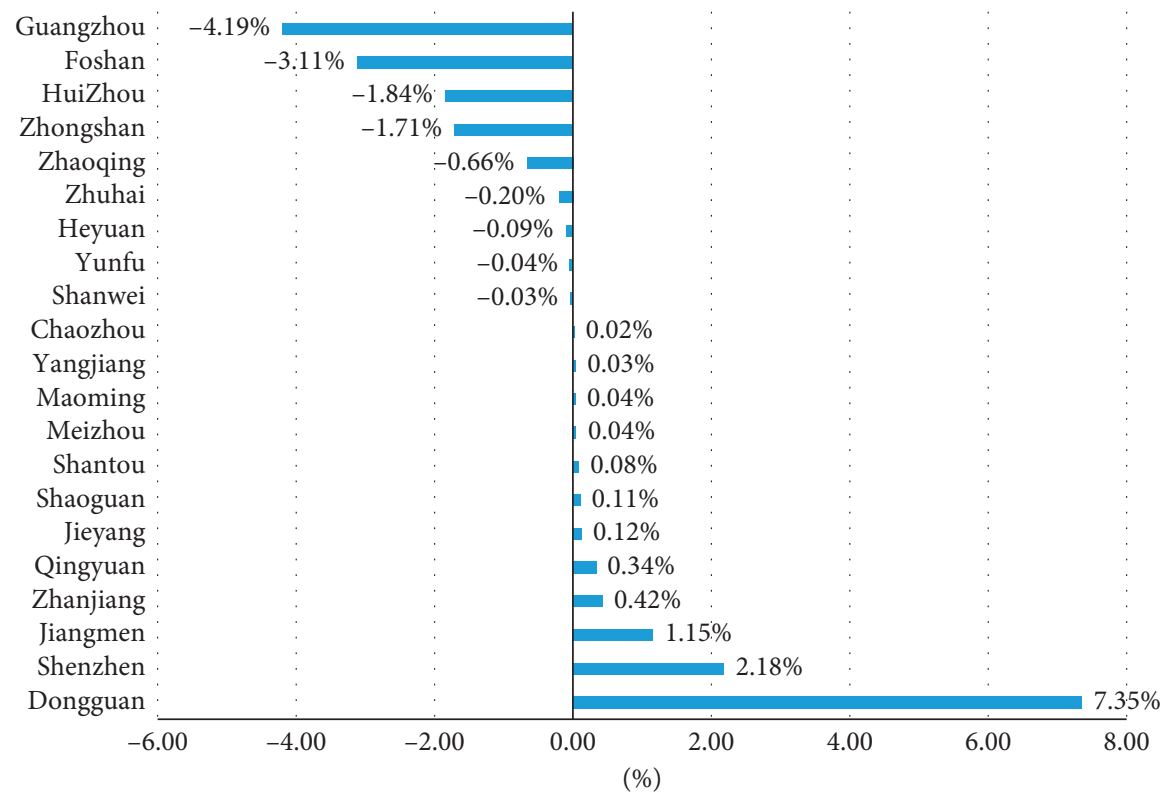

Figure 5: Changes in the output value share of high-tech products in Guangdong Province from 2013 to 2018.

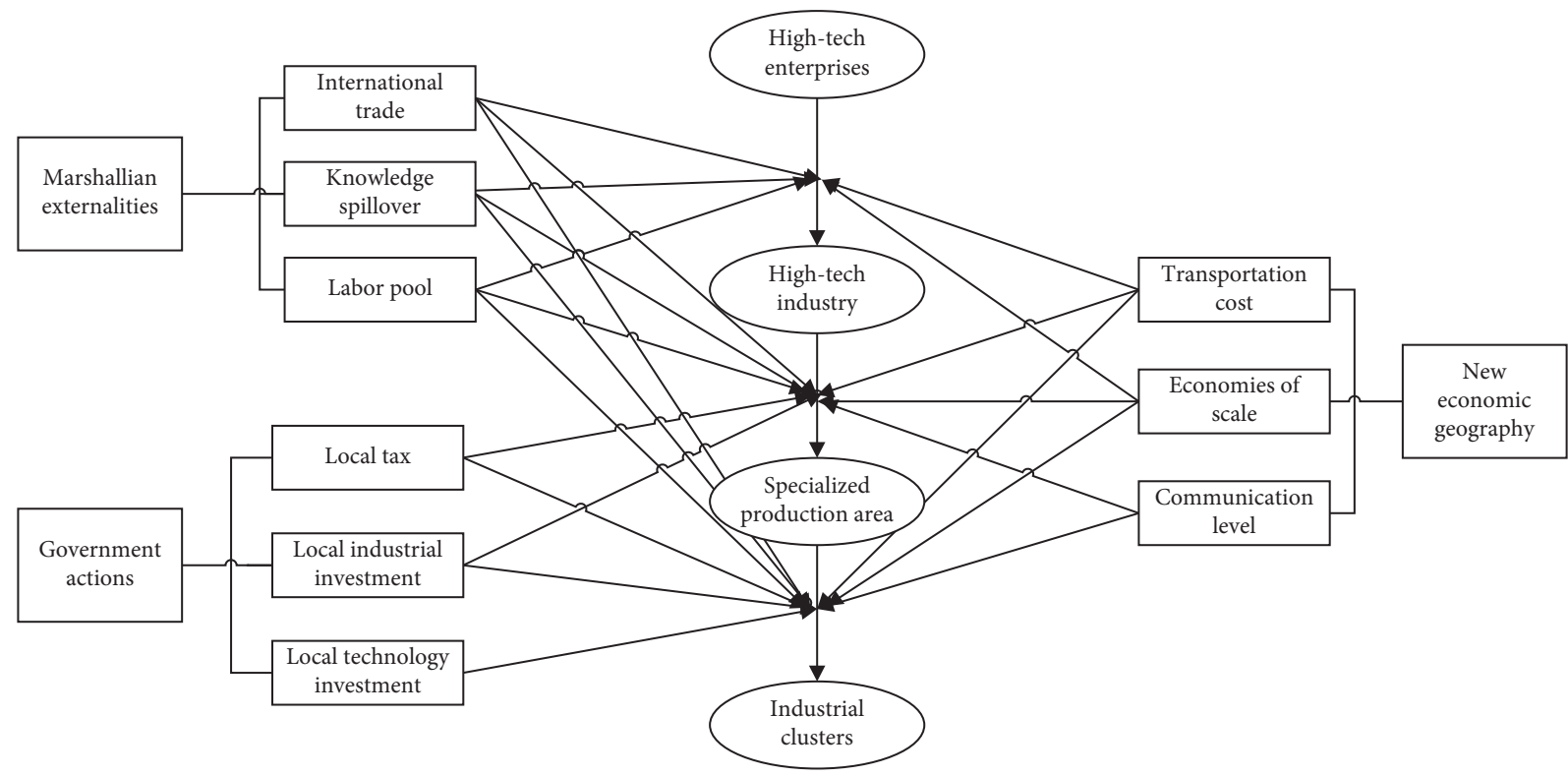

FIgURE 6: Schematic diagram of analysis of the impact mechanism of high-tech industry agglomeration.

of industrial investment in each city, and the proportion of local scientific and technological appropriations in fiscal expenditures to measure government actions.

Based on the above theoretical and mechanism analysis, the following variable table of influencing factors of hightech industry agglomeration is formed (Table 3 ).

\subsection{Empirical Analysis}

4.2.1. Data Sources and Research Methods. The data for the empirical research is extracted from the 2020 Guangdong Statistical Yearbook and the Guangdong Science and Technology Statistics Network. There are many kinds of data processing methods for multiple attributes. Many scholars have done a lot of innovative research in this area, which has brought enlightenment to the research [44-46]. The factor analysis method is employed to study the internal dependence relationship between variables. We use a few abstract variables to reflect the main information represented by many observed variables. The paper uses factor analysis to analyze the factors affecting the agglomeration of high-tech industries.

4.2.2. Data Processing. (1) Practical Test of Factor Analysis. Due to the different measurement units used between the factors that affect the agglomeration of high-tech industries, 
TABLE 3: Variable table of influencing factors of high-tech industry agglomeration.

\begin{tabular}{|c|c|c|}
\hline First-level index & Second-level index & Third-level index \\
\hline \multirow{5}{*}{ Marshall externalities } & International trade & $\begin{array}{l}\text { Total foreign import and export (X1) } \\
\text { Actual use of foreign direct investment amount (X2) }\end{array}$ \\
\hline & \multirow{2}{*}{ Knowledge spillover } & Whole society R\&D investment (X3) \\
\hline & & Number of patent applications granted (X4) \\
\hline & \multirow{2}{*}{ Labor pool } & Total number of employees (X5) \\
\hline & & R\&D personnel of industrial enterprises above designated size (X6) \\
\hline \multirow{3}{*}{$\begin{array}{l}\text { New economic } \\
\text { geography }\end{array}$} & Transportation cost & Highway mileage (X7) \\
\hline & Economies of scale & Regional GDP (X8) \\
\hline & Communication level & Total post and telecommunications business (X9) \\
\hline \multirow{3}{*}{ Government actions } & Local tax & Local general public budget revenue (X10) \\
\hline & Local industrial investment & Proportion of industrial investment in each city (X11) \\
\hline & $\begin{array}{l}\text { Local technology } \\
\text { investment }\end{array}$ & $\begin{array}{l}\text { Proportion of local science and technology appropriations in fiscal expenditure } \\
\text { (X12) }\end{array}$ \\
\hline
\end{tabular}

TABLE 4: KMO and Bartlett's test.

\begin{tabular}{lcc}
\hline & Index & Test value \\
\hline Kaiser-Meyer-Olkin measure of sampling adequacy & & 0.743 \\
& Approx. Chi-square & 776.022 \\
Bartlett's test of sphericity & $\mathrm{d} f$ & 66 \\
& Sig. & 0.000 \\
\hline
\end{tabular}

the original data is processed nondimensionally using SPSS 19.0 software to eliminate the influence of dimension and order of magnitude. Due to constraints on article length, the standardized data is omitted. After data standardization, the applicability test of factor analysis is carried out, as shown in Table 4. According to Table 4, the KMO test value is $0.732>0.7$, the Bartlett test value is 742.189 , and the correlation coefficient significance test Sig. $P$ value is 0.000 . The model is very significant, indicating that it is suitable for factor analysis.

(2) Extracting Principal Components and Factors. After factor extraction, the commonness of the 12 variables appears to be greater than 0.678 , which means that, after factor extraction, at least $67.8 \%$ of the original variable variance can be explained (Table 5). The eigenvalues of the first two factors are 9.822 and 1.136, respectively, which would suggest that the two factors describe 9.578 and 1.117 of the total variances of the original variable 12 , and the variance described by the following factors decreases sequentially. The variance contribution rate of the first factor with eigenvalue greater than 1 reached $79.818 \%$, and the cumulative variance contribution rate of the two factors with eigenvalue greater than 1 reached $89.123 \%$. This would suggest that the two common factors extracted can more comprehensively reflect and represent the factors affecting the agglomeration of high-tech industries in 21 cities in Guangdong Province and can explain the original indicators without losing much information. The effect of extracting principal components and common factors is ideal, as shown in Table 6 and Figure 7.

(3) Factor Loading after Rotation. To understand the composition of each factor, this article uses the maximum variance method to rotate the factor loading matrix. The load of the influence factor after rotation is presented in Table 7
TABle 5: Communalities.

\begin{tabular}{lcc}
\hline & Initial & Extraction \\
\hline$Z$ score (X1) & 1.000 & 0.937 \\
$Z$ score (X2) & 1.000 & 0.936 \\
$Z$ score (X3) & 1.000 & 0.967 \\
$Z$ score (X4) & 1.000 & 0.993 \\
$Z$ score (X5) & 1.000 & 0.904 \\
$Z$ score (X6) & 1.000 & 0.892 \\
$Z$ score (X7) & 1.000 & 0.804 \\
$Z$ score (X8) & 1.000 & 0.963 \\
$Z$ score (X9) & 1.000 & 0.924 \\
$Z$ score (X10) & 1.000 & 0.943 \\
$Z$ score (X11) & 1.000 & 0.754 \\
$Z$ score (X12) & 1.000 & 0.678 \\
\hline
\end{tabular}

Extraction method: principal component analysis.

and Figure 8. It can be seen from Table 7 that the high load indicators on the first common factor $\mathrm{F} 1$ are X1-X6, X8, X9, $\mathrm{X} 10$, and $\mathrm{X} 12$, which represent Marshallian externalities, economies of scale, communication costs, local taxes, local taxes, and local technological inputs, respectively. The high load indicators on the second common factor F2 are X11 and $\mathrm{X} 7$, which represent transportation costs and local industrial investment, respectively.

4.3. Analysis of Empirical Results. The first common factor represents Marshallian externalities: economies of scale, communication costs, local taxation, and local technology investment. However, according to Table 5, the representativeness of local technology investment is less than $70 \%$, so the first common factor can therefore be named Marshallian externalities factor, whose variance contribution rate reached $79.818 \%$, being the key factor affecting the 
TABLE 6: Total variance explained.

\begin{tabular}{|c|c|c|c|c|c|c|c|c|c|}
\hline \multirow{2}{*}{ Component } & \multicolumn{3}{|c|}{ Initial eigenvalue } & \multicolumn{3}{|c|}{ Extraction sums of squared loading } & \multicolumn{3}{|c|}{ Rotation sums of squared loading } \\
\hline & Total & $\%$ of variance & Cumulative \% & Total & $\%$ of variance & Cumulative \% & Total & $\%$ of variance & Cumulative \% \\
\hline 1 & 9.578 & 79.818 & 79.818 & 9.578 & 79.818 & 79.818 & 9.572 & 79.765 & 79.765 \\
\hline 2 & 1.117 & 9.305 & 89.123 & 1.117 & 9.305 & 89.123 & 1.123 & 9.358 & 89.123 \\
\hline 3 & 0.772 & 6.436 & 95.559 & & & & & & \\
\hline 4 & 0.242 & 2.017 & 97.575 & & & & & & \\
\hline 5 & 0.161 & 1.343 & 98.918 & & & & & & \\
\hline 6 & 0.092 & 0.769 & 99.687 & & & & & & \\
\hline 7 & 0.023 & 0.194 & 99.881 & & & & & & \\
\hline 8 & 0.008 & 0.070 & 99.952 & & & & & & \\
\hline 9 & 0.004 & 0.035 & 99.987 & & & & & & \\
\hline 10 & 0.001 & 0.011 & 99.998 & & & & & & \\
\hline 11 & 0.000 & 0.002 & 100.000 & & & & & & \\
\hline 12 & $8.215 E-9$ & $6.845 E-8$ & 100.000 & & & & & & \\
\hline
\end{tabular}

Extraction method: principal component analysis.

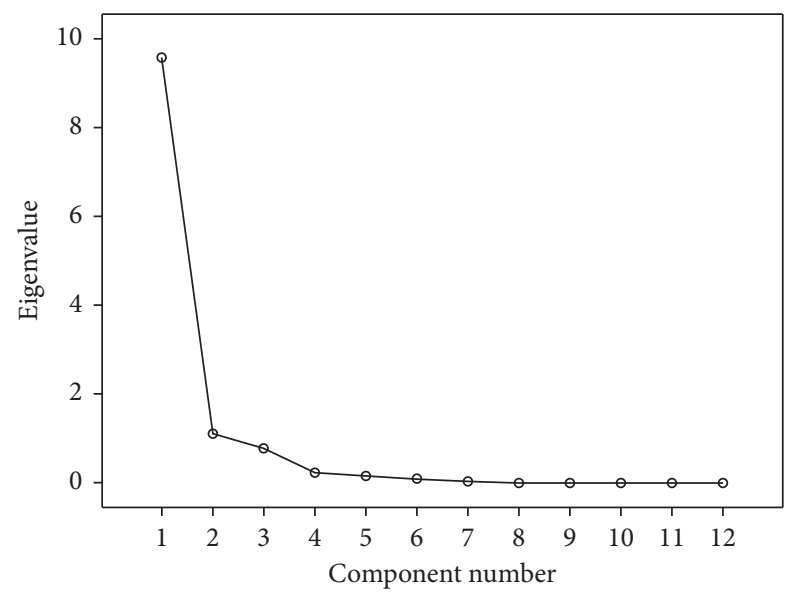

Figure 7: Scree plot.

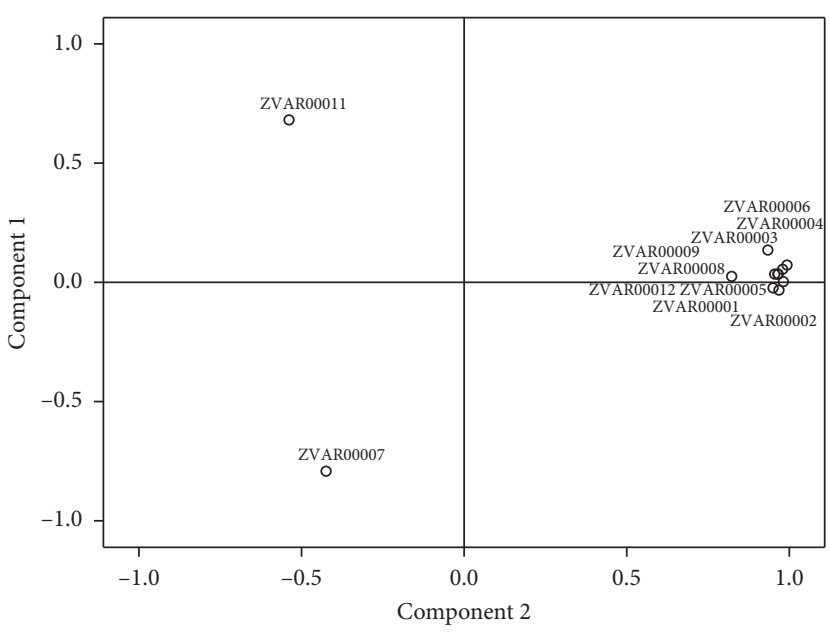

FIGURE 8: Component plot in rotated space.

agglomeration of high-tech industries. The second common factor represents transportation costs and local industrial investment. The factor variance contribution rate is $9.305 \%$. Compared with the first common factor, the effect on the agglomeration of high-tech industries is not significant. Therefore, the main influencing factors of the agglomeration of high-tech industries are Marshallian externalities, economies of scale, communication costs, and local taxation. This 
TABLE 7: Rotated component matrix.

\begin{tabular}{lcc}
\hline & \multicolumn{2}{c}{ Component } \\
& $F_{1}$ & $F_{2}$ \\
\hline$Z$ score (X1) & 0.967 & -0.031 \\
$Z$ score (X2) & 0.967 & -0.031 \\
$Z$ score (X3) & 0.982 & 0.054 \\
$Z$ score (X4) & 0.994 & 0.071 \\
$Z$ score (X5) & 0.951 & -0.023 \\
$Z$ score (X6) & 0.935 & 0.136 \\
$Z$ score (X7) & -0.424 & -0.790 \\
$Z$ score (X8) & 0.981 & 0.006 \\
$Z$ score (X9) & 0.961 & 0.035 \\
$Z$ score (X10) & 0.971 & 0.035 \\
$Z$ score (X11) & -0.536 & 0.683 \\
$Z$ score (X12) & 0.823 & 0.025 \\
\hline Extration
\end{tabular}

Extraction method: principal component analysis. Rotation method: Varimax with Kaiser Normalization. Rotation converged in 3 iterations.

would indicate that, in the formation of Guangdong's hightech industries, Marshall external factors such as international trade cooperation, knowledge spillovers (the input and output of local science and technology in the whole society), and labor pools (especially the number of scientific researchers) play a key role. At the same time, similar to general industrial agglomeration, the formation of high-tech industrial agglomeration is inseparable from economies of scale, communication levels, and local preferential tax policies.

\section{Conclusion and Discussion}

Based on the above empirical and analytical results, we were able to draw the following conclusions and offer a series of recommendations.

First, high-tech industrial clusters evidently play an increasingly important supporting role in promoting economic quality, efficiency, and power. Through research on the agglomeration of high-tech industries in Guangdong Province, this paper was able to offer the conclusion that the agglomeration of high-tech industries in Guangdong Province has gradually increased from 2013 to 2018, and the relationship between high-tech industries becomes closer in geographically adjacent cities. In future development, Guangdong Province should further play the guiding role of the authority to take advantage of the inertia of industrial agglomeration; develop new-generation information technology, artificial intelligence, biomedicine, big data, and other emerging industrial clusters; and optimize the formation of characteristic industrial clusters continuously. It is necessary to increase policy support to attract high-quality enterprises from other provinces to promote the transformation and upgrading of regional industries with high-tech industrial parks, to allow high-quality development. Local governments should create an external environment to be conducive to the formation of high-tech industrial clusters and provide support in financing channels, planning, industrial division, project construction, and policy implementation. Local governments should also formulate policies that are conducive to the cluster development of industrial parks based on regional characteristics to attract high-tech enterprises and support service agencies for the provision of services such as intellectual property certification, quality system certification, and quality and safety system certification for enterprises. It is necessary to continuously break through the administrative constraints on industrial agglomeration and regional policy barriers and form a free and efficient administrative management coordination mechanism. Moreover, regional authorities should adopt taxation, capital, land, and other policies reforms to support the development of small and medium high-tech and private high-tech enterprises to give full play to the radiating and leading role of high-tech industries for the promotion of the overall strength of Guangdong Province's industry.

Second, the agglomeration of high-tech industries in the Pearl River Delta region does appear to be greater, but the agglomeration of cities in the province is subject to dynamic changes, which shows that a certain degree of high-tech industry transfer occurred in the province from 2013 to 2018, but this transfer mainly occurs in the Pearl River Delta region. Guangzhou, Foshan, Huizhou, Zhongshan, and Zhaoqing are the main cities that industrial enterprises transfer from, while Dongguan, Shenzhen, and Jiangmen are the main cities that industrial enterprises transfer to. Therefore, Guangdong Province must coordinate the development among cities in the Pearl River Delta and the cities in all provincial regions and reduce the barriers between regional blockades. Cities in the Pearl River Delta should make good use of the spatial spillover effects brought about by industrial agglomeration to cultivate emerging industries, while the eastern, western, and northern cities of Guangdong Province should seize the opportunity of new infrastructure construction to improve the industrial development environment and further strive for industrial transfer in the Pearl River Delta region. The gap in regional industrial development should be narrowed. After initial industries transfer out, it is necessary to cultivate emerging industries continuously, making good use of geographical space resources, and ensure the extension of the industrial chain. The cities that the industries transfer to must create good development environments for these enterprises to reduce the cost of industry transfer, guide enterprises to improve production technology, and promote a new round of innovative development. Cities should strengthen cooperation in the fields of capital, talents, and technology to create a high-tech industry alliance in the Pearl River Delta in order to build a chain of benefits for upstream and downstream industries, and jointly deal with industry technology and competition problems.

Third, the empirical results from our study show that the agglomeration of high-tech industries is jointly promoted by multiple factors. The regional international trade, knowledge spillover capabilities represented by social science and technology input and patent output, number of local labor forces, especially number of scientific researchers, economies of scale represented by economic aggregates, level of local communications, and preferential tax policies of local governments are some of the main factors affecting the agglomeration of high- 
tech industries. Therefore, in order to increase the agglomeration of high-tech industries, Guangdong must continue to expand its reforms and innovation efforts to encourage the flow of talents, element circulation, and rule docking. The government should continuously optimize the international innovation environment to reduce the landing cost of international innovation resources and attract international innovative talents. It is also equally necessary to establish a production-university-research cooperation network for the establishment of an international business information sharing platform. The government should also promote the efficient flow of knowledge, technology, and information within the industrial cluster, to help companies understand foreign products and market information, and lay the foundation for companies to access the international market. It is necessary to establish a mechanism for stable growth of R\&D investment by using financial investment to mobilize more social capital to join scientific research and development to increase the R\&D expenditure of the whole society. Guangdong should increase the protection of intellectual property rights in order to stimulate innovation and promote high-tech industrial clusters to obtain more breakthroughs in scientific and technological achievements measured in patent output. The local economy should be developed to attract more high-tech enterprises with the scale effect produced by strong economic strength. It is also necessary to improve local communication level with the aim of accelerating the construction of new infrastructure, such as telecommunications and mail service, and smooth communication between high-tech industries and the external environment. Preferential tax policies for high-tech enterprises and additional deductions for research and development expenses should continue to be implemented to stimulate growth and development.

Due to the limitation of data available, we acknowledge that this paper failed to further analyze the agglomeration of specific industries in the high-tech industry in Guangdong Province, such as pharmaceutical manufacturing, electronic information technology, and other subsectors. Therefore, the conclusions of this paper may not be applicable for all industry types and sectors. In addition, the time span of this paper is 2013-2018; thus, what we get is the phase characteristics of this period which may not represent the entire dynamics. If the time dimension can be further elongated, would there be more changes in the agglomeration of high-tech industry? Based on the updated research data, would we be able to obtain a conclusion that is consistent with this paper? Both of these questions need to be further studied and discussed.

\section{Data Availability}

All the data included in this study are available from the corresponding author upon request. Most of the data are already included in the article.

\section{Conflicts of Interest}

The authors declare that there are no conflicts of interest regarding the publication of this paper.

\section{Acknowledgments}

This research was supported by the National Statistical Science Foundation of China (No. 2019LY29), the Characteristic and Innovative Foundation for Humanities and Social Sciences of Education Department of Guangdong Province (No. 2018WTSCX041), and Guangdong Provincial Basic and Applied Basic Research Fund Regional Joint FundYouth Fund Project (No. 2019A1515110683).

\section{References}

[1] Z. J. Wu, S. Liu, H. Z. Dong, and M. R. Liu, "The spatial spillover effect of high-tech industry agglomeration on the quality of regional economic growth," Statistics \& Decision, vol. 21, pp. 126-130, 2019.

[2] K. Paul, "Increasing returns and economic geography," The Journal of Political Economy, vol. 99, no. 3, pp. 483-499, 1991.

[3] G. Ellison and E. L. Glaeser, "Geographic concentration in U. S. manufacturing industries: a dartboard approach," Journal of Political Economy, vol. 105, no. 5, pp. 889-927, 1997.

[4] F. Maurel and B. Sédillot, "A measure of the geographic concentration in French manufacturing industries," Regional Science \& Urban Economics, vol. 29, no. 99, pp. 575-604, 2000.

[5] P. B. Braunerhjelm and J. Dan, "The determinants of spatial concentration: the manufacturing and service sectors in an international perspective," Industry \& Innovation, vol. 10, no. 10, pp. 41-63, 2003.

[6] M. Brülhart and R. Traeger, "An account of geographic concentration patterns in Europe," Regional Science and Urban Economics, vol. 35, no. 6, pp. 597-624, 2005.

[7] A. Leahy, A. Palangkaraya, and J. Yong, "Geographical agglomeration in Australian manufacturing," Regional Studies, vol. 44, no. 3, pp. 299-314, 2010.

[8] E. Paluzie, "Trade policy and regional inequalities," Papers in Regional Science, vol. 80, no. 1, pp. 67-85, 2001.

[9] G. Dumais, G. Ellison, and E. L. Glaeser, "Geographic concentration as a dynamic process," Review of Economics and Statistics, vol. 84, no. 2, pp. 193-204, 2002.

[10] C. F. He, F. H. Pan, and L. Sun, "Geographical concentration of manufacturing industries in China," Acta Geographica Sinica, vol. 62, no. 12, pp. 1253-1264, 2007.

[11] P. Lei, "The convergences and local embeddedness of China's electronic information manufacturing industry- - a study based on provincial panel data," Soft Science, vol. 23, no. 10, pp. 12-16, 2009.

[12] J. R. Baldwin, W. M. Brown, and D. L. Rigby, "Agglomeration economies: microdata panel estimates from Canadian manufacturing*," Journal of Regional Science, vol. 50, no. 5, pp. 915-934, 2010.

[13] G. H. Hanson, "North American economic integration and industry location," Oxford Review of Economic Policy, vol. 14, no. 14, pp. 30-44, 1998.

[14] E. Paluzie, J. Pons, and D. A. Tirado, "Regional integration and specialisation patterns in Spain," Working Papers in Economics, vol. 35, no. 4, pp. 285-296, 2000.

[15] P. P. Combes and M. Lafourcade, Transport Costs Decline and Regional Inequalities: Evidence from France, Social Science Electronic Publishing, Rochester, NY, USA, 2001.

[16] G. H. Hanson, "Market potential, increasing returns and geographic concentration," Journal of International Economics, vol. 67, no. 1, pp. 1-24, 2005. 
[17] M. Bosker, S. Brakman, H. Garretsen et al., "Relaxing Hukou: increased labor mobility and China's economic geography," Journal of Urban Economics, vol. 72, no. 23, pp. 252-266, 2012.

[18] J. Hill and J. L. Naroff, "The effect of location on the performance of high technology firms," Financial Management, vol. 13, no. 1, pp. 27-36, 1984.

[19] G. A. Wood and J. B. Parr, "Transaction costs, agglomeration economies and industrial location," Growth \& Change, vol. 36, no. 1, pp. 34-38, 2005.

[20] S. L. Liu and C. L. Wu, "Study on the location factors of hightech industries agglomeration," Journal of Zhongnan University of Economics and Law, vol. 6, pp. 83-86, 2006.

[21] M. Yao and H. Xu, "The Formation mechanism and demonstration of China's high-tech industry agglomeration," Statistics \& Decision, vol. 1, pp. 105-107, 2008.

[22] X. F. Gao, "Analysis on the agglomeration phenomeno of high and new technology industry," Journal of Nanjing Tech University (Social Science Edition), vol. 10, no. 3, pp. 65-69, 2011.

[23] G. D. Liu, J. Ding, and B. Wu, "Research on chinas high-tech industry cluster upgrading based on global value chain- A case study of biomedical industrial cluster," Soft Science, vol. 25, no. 3, pp. 36-41, 2011.

[24] D. M. Hart, "Founder nativity, founding team formation, and firm performance in the U. S. high-tech sector," International Entrepreneurship and Management Journal, vol. 10, no. 1, pp. 1-22, 2011.

[25] A. Cieślik and M. Ghodsi, "Agglomeration externalities, market structure and employment growth in high-tech industries: revisiting the evidence," Miscellanea Geographica: Regional Studies on Development, vol. 3, no. 19, pp. 76-81, 2015.

[26] A. Zandiatashbar, S. Hamidi, and N. Foster, "High-tech business location, transportation accessibility, and implications for sustainability: evaluating the differences between high-tech specializations using empirical evidence from U. S. booming regions," Sustainable Cities and Society, vol. 50, Article ID 101648, 2019.

[27] G. X. Mao, "Industrial clustering transfer: theoretical review and enlightenment," Statistics \& Decision, vol. 4, pp. 154-157, 2010.

[28] Y. X. Su and M. G. Sun, "The comparison of structural trend on business cost among Jiangsu, Zhejiang and Shanghai and its influence on industrial transfer path," Journal of Nanjing University of Finance and Economics, vol. 4, pp. 15-25, 2011.

[29] H. C. Luo, C. H. Miao, and G. 1. Li Guo, "Review on empirical research and related controversies of different reginal scale industrial transfer," Human Geograph, vol. 1, pp. 1-81, 2014.

[30] C. X. Mao, Q. Liao, C. M. Liu, and L. Cao, "Research on the space path and mechanism of high-tech industrial cluster transfer: a case of Jiangsu province," Economic Geography, vol. 35, no. 12, pp. 105-112, 2015.

[31] Z. S. Cheng, "The guiding path of our country's regional industrial transfer under the new normal of economy," Economic Review Journal, vol. 11, pp. 92-95, 2016.

[32] C. Q. Tao, Y. Z. Peng, and F. Q. Li, "Driving mechanism and spatial effect of industrial gradient transfer promoting technology potential energy agglomeration," China Soft Science, vol. 11, pp. 17-30, 2019.

[33] P. Tu, W. W. Zhao, and J. Z. Liang, "Analysis of space-time transfer and influence factors of high-tech industry in fujian province from perspective of agglomeration and diffusion," Journal of Huaqiao University (Natural Science), vol. 40, no. 2, pp. 257-263, 2019.
[34] H. C. Yang, L. S. Li, and J. Liu, "Industrial agglomeration and total factor productivity of cities in China," Science Research Management, vol. 39, no. 1, pp. 83-94, 2018.

[35] P. Wang and W. M. Wang, "Research on the impact of hightech industry agglomeration on labor productivity-an empirical test based on China's provincial panel data," Journal of East China Normal University: Philosoph, vol. 49, no. 5, pp. 83-94, 2017.

[36] C. J. Zhang, J. Qin, and Y. L. Zhou, "Study on effects of industrial agglomeration on regional innovation under the technology diffusion: based on the angle of value chain in the two stages," Science of Science and Management of S. \&.T. (Monthly), vol. 38, no. 12, pp. 124-132, 2017.

[37] J. Li, H. W. Liu, and Y. Chen, "Industrial agglomeration, technology learning cost and regional economic growthbased on the high-tech industry data in China," Soft Science, vol. 32, no. 4, pp. 95-99, 2018.

[38] L. Y. Guo, J. Z. Huang, and H. M. Zhuang, "Human capital flow, high-tech industrial agglomeration and economic growth," Nankai Economic Studies, vol. 6, pp. 163-180, 2020.

[39] B. Sun, R. Zhang, and H. Mao, "Industrial agglomeration, university-industry collaboration and patent output: evidence from the Chinese high-tech industry," IEEE Access, vol. 8, pp. 228466-228479, 2020.

[40] F. Dong, Y. Wang, L. Zheng, J. Li, and S. Xie, "Can industrial agglomeration promote pollution agglomeration? evidence from China," Journal of Cleaner Production, vol. 246, Article ID 118960, 2020.

[41] G. Ellison, E. L. Glaeser, and W. R. Kerr, "What causes industry agglomeration? evidence from coagglomeration patterns," American Economic Review, vol. 100, no. 3, pp. 1195-1213, 2010.

[42] Q. Han, X. J. Zhang, and W. Q. Xu, “The measure and factor analysis of coagglomeration of chinas industries," Shanghai Journal of Economics, vol. 10, pp. 85-96, 2020.

[43] K. Chen, L. F. Yin, J. Y. Wang, and B. W. Han, "An empirical study on factors of the agglomeration in chinas manufacturing industry," Shanghai Journal of Economics, vol. 10, pp. 97-108, 2020.

[44] S. Zeng, Y. Hu, and X. Xie, "Q-rung orthopair fuzzy weighted induced logarithmic distance measures and their application in multiple attribute decision making," Engineering Applications of Artificial Intelligence, vol. 100, Article ID 104167, 2021.

[45] C. Zhang, W. Su, S. Zeng, T. Balezentis, and E. HerreraViedma, "A two-stage subgroup decision-making method for processing large-scale information," Expert Systems with Applications, vol. 171, Article ID 114586, 2021.

[46] R. Liu, J. Yang, and C. Ruan, "Expected stock return and mixed frequency variance risk premium data," Journal of Ambient Intelligence and Humanized Computing, vol. 11, no. 9, pp. 3585-3596, 2020. 